\title{
A USANS/SANS study of porosity creation and evolution in copper-iron sulphides during hydrothermal mineral-fluid reactions
}

IDOWU A. ADEGOKE ${ }^{1}$, FANG XIA $^{1, *}$, MUHAMMET KARTAL $^{1}$, JITENDRA P. MATA ${ }^{2}$

${ }^{1}$ Discipline of Chemistry and Physics, College of Science, Health, Engineering and Education, Murdoch University, Perth, WA 6150, Australia

(*correspondence: f.xia@murdoch.edu.au)

${ }^{2}$ ACNS, Australian Nuclear Science and Technology

Organisation, Lucas Heights, NSW 2234, Australia

Porosity generation is a common feature of mineral-fluid reactions and it contributes to the formation of orebodies by providing efficient pathways for pervasive hydrothermal fluids to move within the Earth's Crust. However, such reaction-induced porosity is dynamic and its evolution during and after mineral-fluid reactions is still poorly understood. Here we studied the porosity evolution during the hydrothermal replacement of bornite $\left(\mathrm{Cu}_{5} \mathrm{FeS}_{4}\right)$ by secondary copper sulphide minerals using combined (ultra) small-angle neutron scattering (USANS/SANS) measurements and microscopic textural examinations.

Samples reacted under hydrothermal conditions (180-200 ${ }^{\circ} \mathrm{C}, \mathrm{pH}$ 1) for various reaction durations (up to 60 days) were measured by USANS/SANS under both dry conditions and after filling the open pores with contrast matching $\mathrm{H}_{2} \mathrm{O} / \mathrm{D}_{2} \mathrm{O}$ fluid. This enabled the quantification of total porosity (dry measurements), closed porosity (wet measurements), open porosity (total minus closed) and pore size distributions.

All samples contained pores with very broad size distributions from nano to micrometre. Nearly all small pores $(<20 \mathrm{~nm})$ were closed while larger pores were mostly open. The initially porous bornite was replaced with less porous secondary copper sulphide minerals. Once partially reacted, porosity dropped, but with the progressive replacement, porosity increased again, reaching a maximum at complete replacement, and then slowly dropped again, showing porosity creation during the replacement and evolution after the replacement reaction. At longer annealing times (50 days after complete replacement), the abundance of small pores $(<50 \mathrm{~nm})$ decreased while larger pores increased, suggesting the coarsening of small pores as the alteration advances and porosity evolution continued even when the phase abundance didn't significantly change. This study provides insights about porosity evolution in copper-iron sulphides interacting with hydrothermal fluids. 